\title{
Роль коровой контаминации в формировании сумийских базальтов и андезибазальтов Карельской провинции Фенноскандинавского щита
}

\author{
Егорова Ю.С., Арестова Н.А., Кучеровский Г.А., Чекулаев В.П. \\ ИГГД РАН, Санкт-Петербург, axoxyх2014@gmail.com
}

Аннотация. Сумийские базальты и андезибазальты $\left(\mathrm{SiO}_{2}=46-56\right.$ \%, $\mathrm{MgO}=14-4$ \%) Карельской провинции Фенноскандинавского щита обогащены лёгкими Р3Э $\left((\mathrm{La} / \mathrm{Yb})_{\mathrm{N}}=3-15\right)$ и имеют отрицательные значения $\varepsilon_{\mathrm{Nd}}(\mathrm{t}) \mathrm{cp}=-1.5 \pm 1$. Анализ химического и $\mathrm{Sm}-\mathrm{Nd}$ изотопного состава пород и численное моделирование (по РЗЭ) процессов формирования исходных магм показали невозможность получения состава сумийских базальтов только путем коровой контаминации первичных выплавок из деплетированной мантии. Более вероятным представляется существование в начале протерозоя в литосфере под Фенноскандинавским щитом обогащенных участков мантии, сформировавшихся на рубеже мезо-неоархея и отвечающих по составу АтрGrn-перидотиту. Подъем палеопротерозойского плюма 2.5-2.4 млрд. лет назад привел к плавлению неоднородной по составу литосферы и формированию сумийских мафитов и ультрамафитов.

Ключевые слова: Фенноскандинавский щит, Карельская провинция, палеопротерозой, сумий, базальты, андезибазальты, коровая контаминация, $\mathrm{Sm}-\mathrm{Nd}$, метасоматизированная мантия.

\section{The role of crustal contamination in the formation of the early Paleoproterozoic basalts and basaltic andesites from the Karelian province of the Fennoscandian shield}

\author{
Egorova Yu.S., Arestova N.A., Kucherovsky G.A., Chekulaev V.P. \\ IPGG RAS, St.Petersburg, axoxyx2014@gmail.com
}

\begin{abstract}
The early Paleoproterozoic basalts and basaltic andesites ( $\mathrm{SiO} 2=46-56 \%, \mathrm{MgO}=14-4 \%)$ from the Karelian province of the Fennoscandian Shield are enriched in light REE ( $(\mathrm{La} / \mathrm{Yb}) \mathrm{N}=3-15)$ and have negative $\varepsilon_{\mathrm{Nd}}(\mathrm{t}) \mathrm{av} .=-1.5 \pm 1$. Analysis of the chemical and $\mathrm{Sm}-\mathrm{Nd}$ isotope composition of rocks and numerical modeling (based on REE) of the formation processes of initial magmas showed that it was impossible to obtain the composition of these basalts only by crustal contamination of primary melts from the depleted mantle. It seems more likely that the enriched mantle regions existed into the early Paleoproterozoic lithosphere under the Fennoscandian shield. They were corresponding in composition to Amp-Grn-peridotite and formed at the Meso-Neoarchean boundary. Rise of the Paleoproterozoic plume 2.5-2.4 Ga ago led to the melting of the heterogeneous lithosphere and the formation of the early Paleoproterozoic mafic and ultramafic rocks.
\end{abstract}

Key words: Fennoscandian shield, Karelian province, Early Paleoproterozoic, basalts, basaltic andesites, crustal contamination, $\mathrm{Sm}-\mathrm{Nd}$, metasomatized mantle.

\section{Введение}

Сумийский вулканизм был широко проявлен в интервале 2.4-2.5 млрд. лет назад (Светов и др., 2004, 2012; Puchtel et al., 2016; Bogina et al., 2015, 2018; Арестова и др., в печати и др.) на территории всего Карельского кратона Фенноскандинавского щита, независимо от возраста и состава подстилающих пород фундамента. Параллельно с вулканитами, в это же время формировался обширный комплекс интрузивных и дайковых пород основного и ультраосновного состава в Северной Карелии - интрузии Олангской группы и группы Койлисмаа в Финляндии, на юго-востоке Водлозерского домена - Бураковско-Аганозерский массив; в Беломорском поясе - интрузии друзитов; в Кольско-Норвежской провинции - расслоенные интрузии Мончегорского района, ФедоровоПанских тундр и горы Генеральской, вулканиты и дайковый комплекс Полмак-Печенгско-ИмандраВарзугского пояса.

Широкое распространение сумийских базитов и ультрабазитов с высоким содержанием $\mathrm{MgO}$ свидетельствует о масштабном плавлении пород мантии в этот период, очевидно связанном с подъемом плюма. Отличительной чертой сумийских базитов являются отрицательные значения $\varepsilon_{\mathrm{Nd}}(\mathrm{t})$ : друзиты Беломорья (-0.2... -1.9, Lobach-Zhuchenko et al., 1998), вулканиты Ветреного пояса 
(-0.90土0.09, Puchtel et al., 2016) и основные породы расслоенных интрузий Карельского кратона: Бураковская (-1.3... -2.3; Чистяков, Шарков, 2006), Ципринга (-1.1), Луккулайсваара (-2.4), Кивака (-1.2) (Amelin \& Semenov, 1996), расслоенные интрузии Финляндии (-1.6... -2.1, Hanski et al., 2001) и Кольского п-ва: (-0.3...-2.5; Bayanova et al., 2009; Yang et al., 2016). Большинство исследователей объясняют коровые метки в изотопном составе сумийских базитов контаминацией мантийных расплавов при внедрении и последующем фракционировании в коре (Puchtel et al., 2016; Чистяков, Шарков, 2006; Bogina et al., 2018; Арзамасцев и др., 2020 и др.). Однако эти особенности состава, наряду с повышенными концентрациями несовместимых элементов, могут быть обусловлены плавлением обогащенного источника (Bayanova et al., 2009). В этом случае состав сумийских мафитов несет информацию о времени формирования и составе участков обогащенной литосферы архейского кратона Фенноскандинавского щита. Задачей данной работы было оценить степень влияния коровой контаминации на состав сумийских мафитов на примере базальтов и андезибазальтов Карельской провинции с целью охарактеризовать их источник.

\section{Геологическая и петрохимическая характеристика}

В статье рассматриваются сумийские мафические вулканиты Карельской провинции Фенноскандинавского щита: зеленокаменных структур Водлозерского (оз. Эльмус, р. Семчь, д. Койкары, Красная речка, р. Кумса, Каменные озера и Ветреный пояс) и Центрально-Карельского (оз. Воттомукс, Лехта, Шомбозеро) доменов на основе собственных и литературных данных. Вулканиты сумия с угловым несогласием лежат на породах архейского фундамента Карельской провинции, часто в основаниях разреза присутствуют терригенно-обломочные породы (конгломераты и метапесчаники) и перекрываются сариолийскими полимиктовыми конгломератами, в которых они слагают больше 70 \% обломков. Изученные вулканиты образуют многочисленные лавовые потоки (общей мощностью до более 1.5 км (Хейсканен и др., 1977)) с массивной текстурой в нижних частях, пере-

(a)

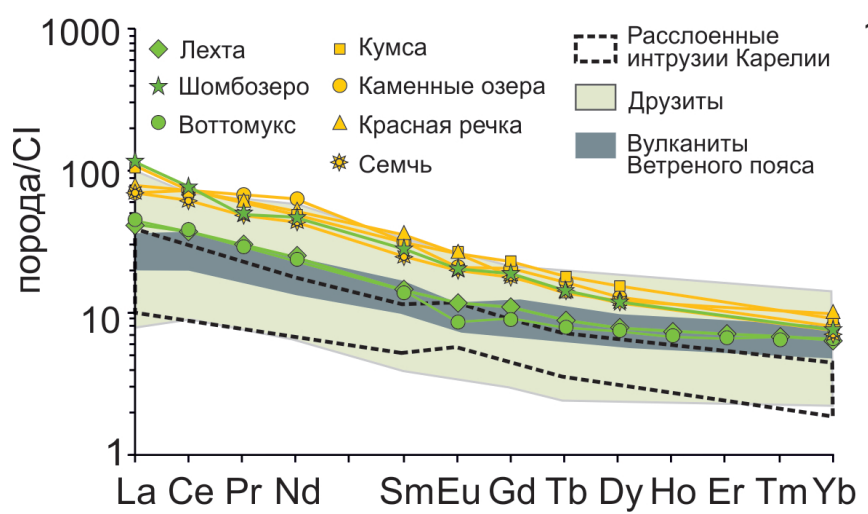

(б)

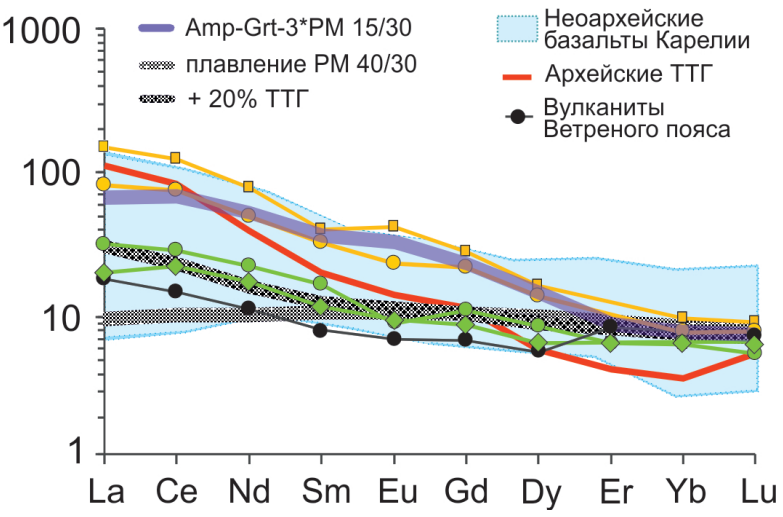

Рис. 1. Спектры распределения Р3Э, нормированные на хондрит СI (по Sun, McDonough, 1989), для средних составов сумийских базальтов Карельской провинции в сравнении: (а) с коматиитовыми базальтами Ветреного пояса (Puchtel et al., 2016), расслоенными интрузиями Карельской провинции (Арестова и др., в печати) и друзитами Беломорской провинции (Lobach-Zhuchenko et al., 1998); (б) - с полем составов неоархейских базальтов (Чекулаев и др., 2018) и средним составом архейских ТТГ (Чекулаев, Глебовицкий, 2017) Карельской провинции, а также рассчитанными спектрами составов расплавов при разных условиях плавления/фракционной кристаллизации и контаминации (подробности в тексте).

Fig. 1. Chondrite-normalized REE patterns (Sun, McDonough, 1989) of the early Paleoproterozoic basalts and basaltic andesites (average compositions) from the Karelian province of the Fennoscandian shield in comparison: (a) with komatiitic basalts of the Vetreny belt (Puchtel et al., 2016), layered intrusions of the Karelian province (Arestova et al., in press), and drusites of the White Sea province (Lobach-Zhuchenko et al., 1998); (b) - with the field of Neoarchean basalts (Chekulaev et al., 2018) and the average composition of the Archean TTG (Chekulaev, Glebovitskiy, 2017) from the Karelian province, as well as calculated REE patterns of melts under different conditions of melting / fractional crystallization and contamination (details in text). 
ходящие в миндалекаменные разности с прослоями пенистых и вариолитовых лав в верхних частях потоков. В строении отельных разрезов присутствуют базальты с подушечными и шаровыми текстурами, вулканические бомбы и кластолавы, что свидетельствует о флюидонасыщенности расплавов.

По химическому составу изученные вулканиты варьируют от коматиитовых базальтов до андезибазальтов $\left(\mathrm{SiO}_{2}=46-56 \%, \mathrm{MgO}=14-4 \%\right)$ с преобладанием последних (Арестова и др., в печати). По сумме щелочей они относятся к породам нормально- и умереннощелочного ряда при $\mathrm{K}_{2} \mathrm{O} /$ $\mathrm{Na}_{2} \mathrm{O}=0.1-0.6$. На диаграмме AFM базальты всех структур лежат в поле пород толеитовой серии. По сравнению с архейскими для сумийских базальтов характерны повышенные (на 2 \%) содержания $\mathrm{SiO}_{2}$ при тех же концентрациях $\mathrm{MgO}$ и широкие вариации магнезиальности с $\mathrm{mg} \#$ от 0.40 до 0.69 (Арестова и др., в печати; Lobach-Zhuchenko et al., 1998; Bogina et al., 2015, 2018).

Все вулканиты характеризуются относительно высокими концентрациями $\mathrm{Sr}$ и $\mathrm{Zr}, \mathrm{Ti} /$ $\mathrm{Zr}$ отношением, близким к 60, и обогащены лёгкими Р3Э с $(\mathrm{La} / \mathrm{Yb})_{\mathrm{N}}=3-15$, при $(\mathrm{La} / \mathrm{Sm})_{\mathrm{N}}=2-4$, $(\mathrm{Tb} / \mathrm{Yb})_{\mathrm{N}}=1.3-2.3, \mathrm{Sm} / \mathrm{Nd}=0.19-0.21$. Самые высокие концентрации РЗЭ наблюдаются в наименее магнезиальных вулканитах Кумсинской структуры, а наименьшие - в наиболее магнезиальных вулканитах Лехтинской структуры, р-на оз. Воттомукс и Ветреного пояса при практически параллельных графиках распределения РЗЭ (рис. 1). Все базитовые вулканиты сумия характеризуются отрицательной аномалией $\mathrm{Nb}$ с отношением $\mathrm{Nb} / \mathrm{La}=0.7-0.5$ (Арестова и др., в печати). На диаграмме $\mathrm{Zr} / \mathrm{Y}-\mathrm{Nb} / \mathrm{Y}$ (Condie, 2005) составы сумийских базальтов и андезибазальтов попадают в поле производных обогащенной относительно ДМ субконтинентальной литосферной мантии (EN) и верхнекоровых составов.

\section{Sm-Nd изотопная характеристика}

Все сумийские базальты и андезибазальты Карельского кратона характеризуются сходными отрицательными значениями $\varepsilon_{\mathrm{Nd}}(\mathrm{t})=-0.5--3.8$ (Центрально-Карельский домен) и $\varepsilon_{\mathrm{Nd}}(\mathrm{t})=-0.5--3.6$ (Водлозерский домен, искл. 2 обр. p-на Красной речки с $\varepsilon_{\mathrm{Nd}}(\mathrm{t})=+1.2$ и +0.8$)$ (рис 2), а также пониженными отношениями ${ }^{147} \mathrm{Sm} /{ }^{144} \mathrm{Nd}=0.09-0.14$ в сравнении с базальтами архейских зеленокаменных поясов (0.17-0.23), которые не зависят от возраста и состава подстилающих коровых пород. Значительные вариации значений $\varepsilon_{\mathrm{Nd}}(\mathrm{t})$ базальтов для некоторых структур, в том числе в пределах одного потока вулканитов (например, для района Красной речки $\left.\varepsilon_{\mathrm{Nd}}(\mathrm{t})=+1.2--3.8\right)$, могут свидетельствовать о нарушениях изотопной системы части образцов во время метаморфических процессов (Арестова и др., в печати). Большинство образцов имеют значения $\varepsilon_{\mathrm{Nd}}(\mathrm{t})=-1.5 \pm 1$ и в координатах ${ }^{147} \mathrm{Sm} /{ }^{144} \mathrm{Nd}-{ }^{143} \mathrm{Nd} /{ }^{144} \mathrm{Nd}$ образуют линейную зависимость, отвечающую возрасту $\square 2.45$ млрд. лет.

\section{Обсуждение}

Присутствие в составе изученных базальтов высокомагнезиальных разновидностей (\#mg ок. 60, при Cr 300-1000 г/т, Ni 200-300г/T), коматиитов в Ветреном поясе с содержанием $\mathrm{MgO} \square 20$ вес. \% (Puchtel et al., 2016) свидетельствует о мантийном источнике исходных расплавов. Одни исследователи предполагают, что им была деплетированная литосферная мантия (ДМ) (Puchtel et al., 2016; Bogina et al., 2018 и др.), другие, основываясь на изотопных данных, утверждают плюмовую природу первичного мантийного вещества (Yang et al., 2016). В обоих случаях предполагается необогащенный мантийный источник с положительными значениями $\varepsilon_{\mathrm{Nd}}$ на момент плавления $(+2.6-+4)$. Для объяснения повышенных концентраций несовместимых элементов и отрицательных значений $\varepsilon_{\mathrm{Nd}}(\mathrm{t})$ в первично мантийных расплавах привлекается коровая контаминация. Расчёты для вулканитов Ветреного пояса (Puchtel et al., 2016) показали возможность происхождения наиболее примитивных коматиитовых лав $\left(\mathrm{MgO}=27\right.$ вес. \%, $\mathrm{Nd}=5.5 \pm 0.2$ г/т, $\left.\varepsilon_{\mathrm{Nd}}(2.41)=-0.9 \pm 0.9\right)$ из деплетированного мантийного источника с $\varepsilon_{\mathrm{Nd}}(2.41)=+3.7 \pm 0.3$ с последующей $\square 4 \%$ контаминацией палеоархейским тоналитом Водлозерского домена с $\varepsilon_{\mathrm{Nd}}(2.41)=-9.5 \pm 0.6$. Сложнее получить отрицательные значения $\varepsilon_{\mathrm{Nd}}(\mathrm{t})$ вулканитов и друзитов, прорывающих более молодую кору Центрально-Карельского домена и Беломорской провинции с $\varepsilon_{\mathrm{Nd}}(2.45)-2.5 \pm 1$. Для этого необходим больший объем контаминанта (> 10 \%) (рис. 2), однако, при объемах свыше 20 \% нарушается баланс масс по главным элементам, как было показано для друзитов (Lobach-Zhuchenko et al., 1998). Более того, сумийские ан- 


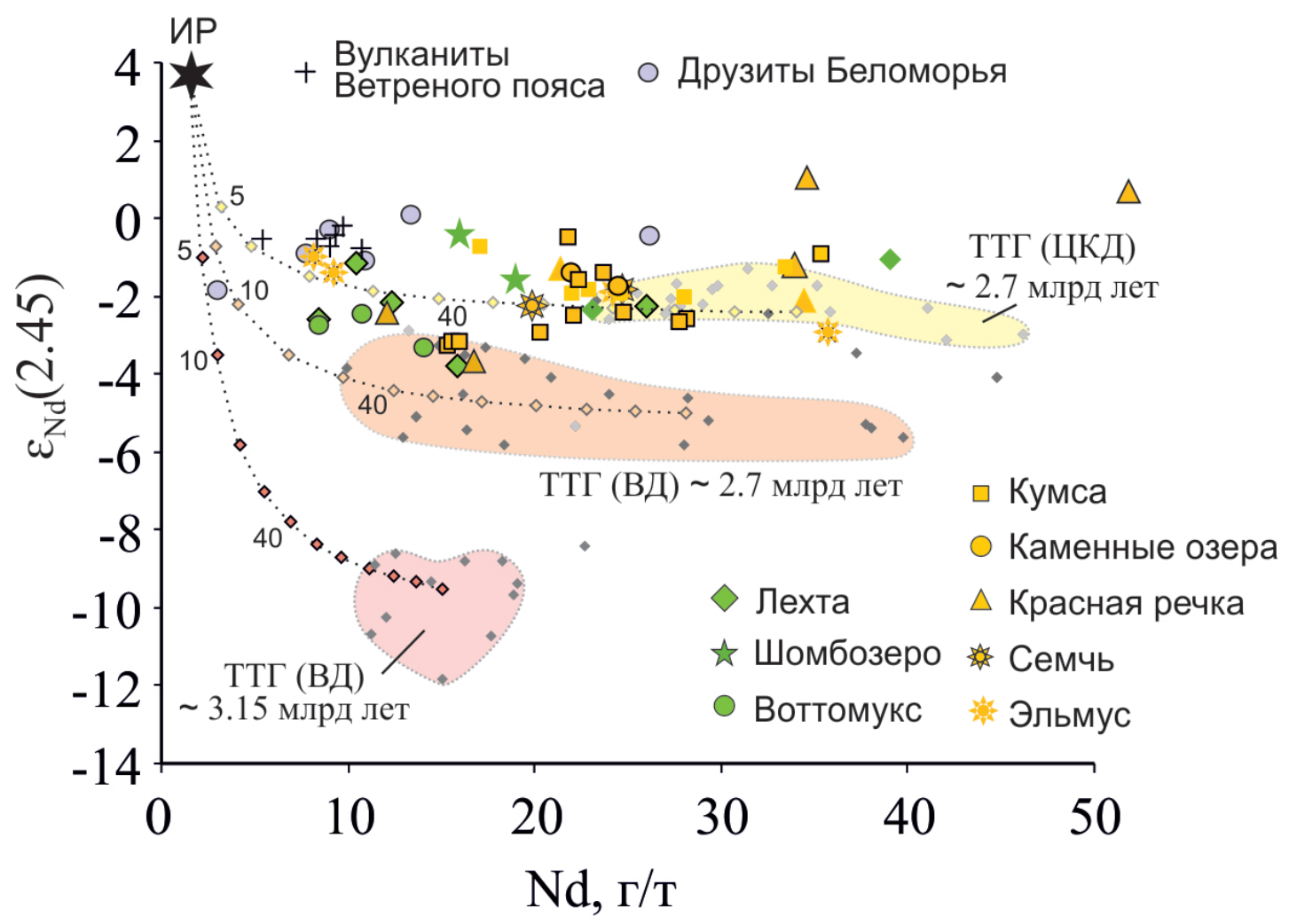

Рис. 2. Диаграмма в координатах $\mathrm{Nd}-\varepsilon_{\mathrm{Nd}}(2.45)$ для сумийских базальтов (Арестова и др., в печати, Bogina et al., 2015, 2018) в сравнении с базальтами Ветреного пояса (Puchtel et al., 2016), друзитами Беломорья (LobachZhuchenko et al., 1998) и составами архейских ТТГ пород Карельской провинции (значения $\varepsilon_{\mathrm{Nd}}$ пересчитаны на 2.45 млрд. лет).

Приведены линии, рассчитанные по математической модели двухкомпонентного смешения (Jahn et al., 2000): $X m=[(\varepsilon c-\varepsilon m c) \mathrm{Nd} c] /[\varepsilon m c(\mathrm{Nd} m-\mathrm{Nd} c)-(\varepsilon m \mathrm{Nd} m-\varepsilon c \mathrm{Nd} c)]$, где $X m-$ доля мантийного компонента, $\mathrm{Nd} m$ и $\mathrm{Nd} c-$ концентрация $\mathrm{Nd}$ в мантийном и коровом компонентах, $\varepsilon m c, \varepsilon m, \varepsilon c-$-значения для полученной корово-мантийной смеси, мантийного и корового компонентов соответственно, пересчитанных на возраст (2.45 млрд. лет) сумийского магматизма. При расчетах в качестве корового компонента был принят средний состав (1) палеоархейских тоналитов Водлозерского домена (ВД) с $\varepsilon \mathrm{Nd}(2.45)=-9.5$ и $\mathrm{Nd}=15$ г/т; (2) неоархейских гранитоидов ВД $\varepsilon \mathrm{Nd}(2.45)=-5$ и $\mathrm{Nd}=28$ г/т; (3) неоархейских гранитоидов Центрально-Карельский домена (ЦКД) $\varepsilon \mathrm{Nd}(2.45)=-2.4$ и $\mathrm{Nd}=38$ г/т, а в качестве мантийного компонента в модели был использован состав рассчитанного исходного (неконтаминированного) расплава (ИР) для коматиитовых базальтов Ветреного пояса (Puchtel et al., 2016) с $\varepsilon N d(2.45)=+3.7, \mathrm{Nd}=1.44$ г/т.

Fig. 2. $\mathrm{Nd}$ vs $\varepsilon \mathrm{Nd}(2.45)$ diagram for the early Paleoproterozoic basalts and basaltic andesites from the Karelian province of the Fennoscandian shield (Arestova et al., In press, Bogina et al., 2015, 2018) in comparison with basalts of the Vetreny belt (Puchtel et al., 2016), drusites of the White Sea region (Lobach- Zhuchenko et al., 1998) and the Archean TTG rock compositions of the Karelian province ( $\varepsilon \mathrm{Nd}$ values are recalculated to $2.45 \mathrm{Ga}$ ).

Mixing lines calculated using the mathematical model of two-component mixing (Jahn et al., 2000): Xm $=[(\varepsilon \mathrm{c}-\varepsilon \mathrm{mc})$ $\mathrm{Ndc}] /[\varepsilon \mathrm{mc}(\mathrm{Ndm}-\mathrm{Ndc})-(\varepsilon \mathrm{mNdm}-\varepsilon \mathrm{cNdc})]: \mathrm{Xm}$ is the mantle component, $\mathrm{Ndm}$ and $\mathrm{Ndc}$ are the $\mathrm{Nd}$ concentration in the mantle and crustal components, $\varepsilon \mathrm{mc}, \varepsilon \mathrm{m}, \varepsilon \mathrm{c}$ are the values for the obtained crustal-mantle mixture, mantle and crustal components, respectively, recalculated for the age $(2.45 \mathrm{Ga})$. The crustal component: average composition (1) of the Paleoarchean tonalites of the Vodlozero domain (VD) with $\varepsilon N d(2.45)=-9.5$ and $\mathrm{Nd}=15 \mathrm{ppm}$; (2) Neoarchean granitoids $\mathrm{VD} \varepsilon \mathrm{Nd}(2.45)=-5$ and $\mathrm{Nd}=28 \mathrm{ppm}$; (3) Neoarchean granitoids of the Central Karelian domain (CKD) $\varepsilon N d$ $(2.45)=-2.4$ and $\mathrm{Nd}=38 \mathrm{ppm}$, and the composition of the calculated initial (uncontaminated) melt for the komatiite basalts of Vetreny belt was used as the mantle component in the model with $\varepsilon N d(2.45)=+3.7, \mathrm{Nd}=1.44 \mathrm{ppm}$ (Puchtel et al., 2016). 
дезибазальты Карельской провинции от коматиитов Ветреного пояса и одновозрастных базитов интрузий отличают высокие концентрации $\mathrm{Nd}=8-51$ г/т (ср. 22) (рис. 1, 2), сопоставимые с таковыми в коре, поэтому их состав не мог быть получен путем только контаминации деплетированных мантийных расплавов материалом ТТГ-коры (рис. 2).

Этот вывод подтверждается расчетами моделей плавления с последующей фракционной кристаллизацией и коровой контаминацией по РЗЭ. Для расчета равновесного частичного плавления по редким элементам была применена методика (Allegre, Minster, 1978), использованы данные из экспериментальных работ (Walter, 1998; Nandedkar et al., 2016), содержание РЗЭ в мантийном перидотите принято равным PM (Sun, McDonough, 1989). Наименее обогащенные спектры распределения РЗЭ сумийских базальтов Ветреного пояса, Лехтинской структуры и оз. Воттомукс можно получить при 35-40 \% плавлении перидотита с последующем удалением 30 \% O1-OРх котектики и добавлением до 20 \% корового контаминанта (рис. 1 б). Но ни меньшая степень плавления, ни большее фракционирование не могут обеспечить наблюдаемые высокие концентрации и характер распределения РЗЭ в базальтах Водлозерского домена, содержание РЗЭ в которых в отдельных случаях даже превышает таковое в ТТГ (рис. 1 б). Поэтому некоторые исследователи (Bogina et al., 2018) выбирают в качестве контаминанта неоархейские санукитоиды, обогащенные LREE (в т.ч. Nd). Однако санукитоиды с содержанием $\mathrm{Nd}>40$ г/т характерны лишь для некоторых малых массивов и имеют очень ограниченное распространение, тогда как большинство санукитоидов (Lobach-Zhuchenko et al., 2005; Heilimo et al., 2010; Егорова, 2014) не отличаются по содержанию Nd (20-30 г/т) от других неоархейских гранитоидов Карельского кратона (рис. 2). Следовательно, санукитоиды также не подходят в качестве универсального контаминанта для получения наблюдаемых составов сумийских вулканитов всех изученных структур.

С другой стороны, повышенное содержание $\mathrm{SiO}_{2}$, ЛРЗЭ и $\mathrm{Zr}$, наличие отрицательной аномалии $\mathrm{Nb}$, высокое отношение $(\mathrm{La} / \mathrm{Sm})_{\mathrm{N}}=2-4$ и низкие отношения $\mathrm{Sm} / \mathrm{Nd}=0.19-0.21$ и $\mathrm{Nb} / \mathrm{La}=0.7-0.5$ помимо коровой контаминации могут свидетельствовать о выплавлении первичных расплавов из обогащенного мантийного источника с последующим фракционированием амфибола. Это согласуется с водонасыщенностью сумийских базальтовых лав, о чем свидетельствуют миндалекаменные текстуры, проявленные в ряде потоков. По данным экспериментов при давлениях ниже 3 ГПа и $T<1200^{\circ} \mathrm{C}$ в литосферной мантии может существовать паргасит (Green, 2015), который должен неизбежно разрушаться при высоких температурах поднимающегося плюма и насыщать область плавления водой. Согласно расчетам, обогащенные спектры распределения РЗЭ сумийских базальтов Водлозерского домена можно получить при 15 \% плавлении амфибол содержащего гранатового перидотита, в 3 раза обогащенного РЗЭ в сравнении с РМ, с последующим фракционированием Px и Amp (10-30 \%) (сиреневая линия, рис. 1б). Присутствие амфибола в источнике сумийских базальтов могло обусловить их отличия от мезоархейских аналогов, которые выплавлялись при большем давлении (3.5-5 ГПа, Арестова и др., 1988) и не несут следов обогащения и/или контаминации.

Производные обогащенной литосферной мантии в истории Фенноскандинавского щита появляются в начале неоархея. Неоархейские базальты Карельской провинции в сравнении с мезоархейскими имеют обогащённые тренды распределения РЗЭ (Чекулаев и др., 2018), сходные с таковыми в сумийских базитах (рис. 1б). Широкое проявление санукитоидного магматизма $\square 2.73$ млрд. лет назад на территории всего архейского кратона (Lobach-Zhuchenko et al., 2005; Heilimo et al., 2010; Егорова, 2014) свидетельствует о существовании на этот момент в литосфере метасоматизированных областей. Примитивные мафитовые фазы санукитоидных массивов имеют значения $\varepsilon_{\mathrm{Nd}}(2.73)=+1.7 \pm 0.5$, свидетельствующие наряду с другими изотопными характеристиками (Егорова, 2014) об обогащении источника незадолго до его плавления. Отрицательные значения $\varepsilon_{\mathrm{Nd}}(\mathrm{t})$ в сумийских базитах могут быть результатом эволюции такого источника (с пониженным относительно хондрита и ДМ Sm/Nd отношением). Разная степень обогащения и/или плавления мантийного источника могли приводить к наблюдаемым отличиям в составе вулканитов различных структур. 


\section{Заключение}

Сходные геохимические и изотопные характеристики вулканитов и интрузий, локализованных в различных фрагментах коры Фенноскандинавского щита, имеющих различный возраст и состав подстилающих/вмещающих пород, требуют единых или, по крайней мере, сходных условий формирования расплавов.

Коровая контаминация, вероятно, имела место, однако этот механизм не подходит для объяснения всех наблюдаемых особенностей состава сумийских вулканитов, в первую очередь, высоких концентраций легких РЗЭ, в том числе $\mathrm{Nd}$.

Плавление обогащенного в позднем архее мантийного источника является более подходящим объяснением повышенных концентраций несовместимых элементов и отрицательных значений $\varepsilon_{\mathrm{Nd}}(\mathrm{t})$ в сумийских базитах.

Работа выполнена в рамках темы НИР № FMNU-2019-0001.

\section{Литература}

1. Арестова Н.А., Лобач-Жученко С.Б., Кузнецов Р.А. Расчёт петрологических моделей коматиитов и базальтов с использованием содержаний редких элементов. В: (Лобач-Жученко С.Б. ред.) Зеленокаменные пояса фундамента Восточно-Европейской платформы. 1988. Л. Изд-во: Наука. С. 148-162.

2. Арестова Н.А., Чекулаев В.П., Егорова Ю.С., Кучеровский Г.А., Крамчанинов А.Ю. Сумийские базальты Карельской провинции: геологическое положение, состав, условия образования // Петрология. В печати.

3. Арзамасцев А.А., Егорова С.В., Ерофеева К.Г., Самсонов А.В., Степанова А.В., Скуфьин П.К., Чащин В.В., Веселовский Р.В. Палеопротерозойские (2.51-2.40 млрд. лет) магматические провинции северо-восточной Фенноскандии: геохимия вулканитов и корреляция с интрузивными комплексами // Стратиграфия. Геол. корреляция. 2020. Т. 28. № 6. С. 37-66.

4. Егорова Ю.С. Санукитоиды Фенно-Карельской провинции Балтийского щита: геология, состав, источники. Автореф. канд. дисс. С.-Петербург. 2014. 20 с.

5. Светов С.А., Голубев А.И., Светова А.И. Геохимия сумийских андезибазальтов Центральной Карелии // Геохимия. 2004. № 7. Т. 42. С. 729-739.

6. Светов С.А., Светова А.И., Назарова Т.Н. Сумийские андезибазальты Койкарско-Эльмусской площади: литогеохимическая характеристика и условия формирования // Геология и полезные ископаемые Карелии. Петрозаводск. 2012. Вып. 15. С. 5-27.

7. Хейсканен К.И., Голубев А.И., Бондарь Л.Ф. Орогенный вулканизм Карелии // Труды Ин-та геологии Кар ФАН СССР. 1977. Вып. 36. 216 с.

8. Чекулаев В.П., Арестова Н.А., Егорова Ю.С., Кучеровский Г.А. Изменение условий формирования коры Карельской провинции Балтийского щита при переходе от мезо- к неоархею: результаты геохимических исследований // Стратиграфия. Геол. корреляция. 2018. Т. 26. № 3. С. 3-23.

9. Чекулаев В.П., Глебовицкий В.А. О среднем составе ТТГ (тоналит-трондьемит-гранодиоритовой) ассоциации: возможности использования // Доклады РАН. 2017. Т. 472. № 2. С. 192-196.

10. Чистяков А.В., Шарков Е.В. Петрология раннепалеопротерозойского Бураковского комплекса, Южная Карелия // Петрология. 2008. Т. 16. № 1. С. 66-91.

11. Alapieti T. The Koilismaa layered igneous complex, Finland - its structure, mineralogy and geochemisty, with specialemphasis on the distribution of chromium // Geol. Surv Finl. Bull. 1982. V. 319. P. 1-116.

12. Allegre C.J., Minster J.F. Quantitative models of trace element behavior in magmatic process // Earth and Planetary Science Letters. 1978. № 38. P. 1-25.

13. Bayanova T., Ludden J., Mitrofanov F. Timing and duration of Palaeoproterozoic events ore-bearing layered intrusions of the Baltic Shield: metallogenic, producing petrological and geodynamic implications // Geological Society, London. Special Publication. 2009. V. 323. P. 165-198.

14. Bogina M.M., Zlobin V.L., Mints M.M. Early Paleoproterozoic volcanism of the Karelian Craton: age, coerces and geodynamic setting // International Geology Review. 2015. V. 57. №. 11-1. P. 1433-1445. DOI: $10.1080 / 00206814.2014 .931783$.

15. Bogina M., Zlobin V., Svetov S., Sharkov E., Chistyakov A. Petrogenesis of siliceous high-Mg series: Evidence from Early Paleoproterozoic mafic volcanic rocks of the Vodlozero Domain, Fennoscandian Shield // Geoscience Frontiers. 2018. № 9. P. 207-221.

16. Condie K.C. High field strength element ratios in Archean basalts: A window to evolving sources of mantle plumes? // Lithos. 2005. V. 79. P. 491-504.

17. Green D.H. Experimental petrology of peridotites, including effects of water and carbon on melting in the Earth's upper mantle // Phys. Chem. Mineral. 2015. V. 42. P. 95-122. 
18. Hanski E., Huhma H., Rastas P., Kamenetsky V.S. The Palaeoproterozoic komatiite-picrite association of Finnish Lapland // J. Petrol. 2001. V. 42. P. 855-876.

19. Heilimo E., Halla J., Hölttä P. Discrimination and origin of the sanukitoid series: Geochemical constraints from the Neoarchean western Karelian Province (Finland) // Lithos. 2010. V. 115. P. 27-39.

20. Jahn B.M., Wu F., Chen B. Massive granitoid generation in Central Asia: Nd isotope evidence and implication for continental growth in Phanerozoic // Episodes. 2000. V. 23. P. 82-92.

21. Lobach-Zhuchenko S.B., Rollinson H.R., Chekulaev V.P., Arestova N.A., Kovalenko A.V., Ivanikov V.V., Gooseva N.S., Sergeev S.A., Matukov D.I., Jarvis K.E. High-Mg granitoids (sanukitoids) of the Baltic shield - geological setting, geochemical characteristics and implication for the origin of mantle derived melt // Lithos. 2005. V. 79. P. 107-128.

22. Lobach-Zhuchenko S.B., Arestova N.A., Chekulaev V.P., Levsky L.K., Bogomolov E.S., Krylov I.N. Geochemistry and petrology of 2.40-2.45 Ga magmatic rocks in the north-western Belomorian Belt, Fennoscandian Shield, Russia // Precambrian. Res. 1998. V. 92. № 3. P. 223-250.

23. Nandedkar R.H., Hürlimann N., Ulmer P., Muntener O. Amphibole-melt trace element partitioning of fractionating calc-alkaline magmas in the lower crust: an experimental study // Contrib. Mineral. Petrol. 2016. V. 171. I. 71. P. 1-25. https://doi.org/10.1007/s00410-016-1278-0.

24. Puchtel I.S., Touboul M., Blitchert-Toft J., Walker R.J., Brandon A.D., Nicklas R.W., Kulikov V.S., Samsonov A.V. Lithophile and siderophile element systematics of Earth's mantle at the Archean-Proterozoic boundary: Evidence from 2.4 Ga komatiites // Geochim. Cosmochim. Acta. 2016. V. 180. P. 227-255.

25. Sun S., McDonough W.F. Chemical and isotopic systematic of oceanic basalts: implications for mantle composition and processes. In: Magmatism in the ocean basins // Geol. Society. Spec. Publ. 1989. V. 42. P. 313-345.

26. Walter M. J. Melting of garnet peridotite and the origin of komatiite and depleted lithosphere // Journal of Petrology. 1998. V. 39. P. 29-60.

27. Yang S-H., Hanski E., Li C., Maier W.D., Huhma H., Makrushin A., Latypov R., Lohaye Y., O’ Brion Qu W-J. Mantle source of the 2.44-2.50 Ga mantle plume-related magmatism in the Fennoscandian Shield: evidence from Os, Nd, and Sr isotope compositions of the Monchepluton and Kemi intrusions // Mineral. Deposita. 2016. V. 51. P. 1055-1073. 